\title{
Design of a Turbofan Powered Transport Aircraft
}

\author{
Final Report \\ NASA/USRA Advanced Design Project \\ School of Aeronautics and Astronautics \\ Purdue University \\ West Lafayette, Indiana
}

Regional

HOQ GRATT

YN-OS-CR

78269

Abstract

The majority of the market for small commercial transport aircraft is dominated by high-efficiency, propeller-driven aircraft of non-U.S. manufacture. During the past year senior student design teams at Purdue developed and then responded to a Request For Proposal (RFP) for a regional transport aircraft. The RFP development identified promising world markets and their needs. The students responded by designing aircraft with ranges of up to 1500 nautical miles and passenger loads between 50 and 90 . During the design project, special emphasis was placed upon keeping acquisition cost and direct operating costs at a low level while providing passengers with quality comfort levels. Twelve student teams worked for one semester developing their designs. This final report describes several of the designs that placed a high premium on innovation.

Background - The regional airline industry

The Federal Aviation Administration defines the regional transport industry as "those air carriers that provide regularly scheduled passenger service and whose fleets are composed predominantly of aircraft having 60 seats or less." The regional transport industry's primary goal is to provide air transport from small secondary airports to large metropolitan and inter- national airports served by commercial air carriers. The market for aircraft to perform this mission is dominated by high-efficiency, propellerdriven aircraft, with the bulk of the aircraft manufactured by companies outside the United States.

Since airline deregulation began in the late 1970's the differences between regional airlines with small aircraft and larger air carriers have become less distinct. In 1978, regional
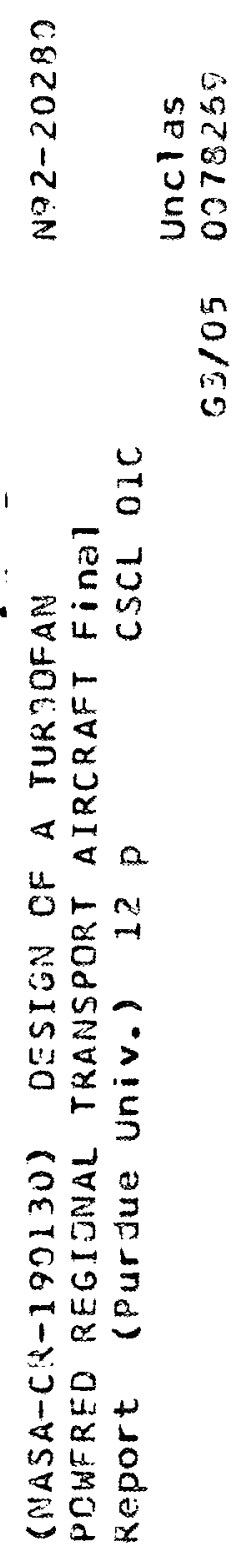
airlines operated at a level of approximately 49,500 passengers per carrier. By 1988 this average had risen to 180,200 , an increase of $205 \%$. This growth of the regional industry outpaced the other parts of the commercial airline industry. The Federal Aviation Administration (FAA) predicts that the number of revenue passenger miles on regional carriers will nearly double between 1988 and the year 2000.

Areas of high growth are likely to be in Europe and Asia, and, to a lesser extent, the United States. However, in the U.S. there is a greater acceptance of the regional airline industry by the public and increasing numbers of commercial partnership agreements, called code-sharing, between small carriers and the major carriers. These agreements are essential to the survival of regional airlines because their financial health is tied to the health of the major airline partner. In 1989,43 of the 50 largest regional companies participated in code-sharing agreements with major carriers.

The European industry today resembles the U.S. industry immediately after deregulation. European traffic has had recent growth increases near
17 per cent per year. European airlines have not yet begun the U.S. practice of code-sharing, but it is only a matter of time before this occurs.

In general, world growth of regional traffic, including Asia, is expected to remain healthy and growing into the foreseeable future. The number of new units required to fill demand for new aircraft and replacements for older aircraft has been predicted to be as high as 6000 aircraft through 1998.

On the other hand, problems such as airport congestion have occurred as an increasing amount of air traffic has been scheduled to converge at major hub airports in the United States and in Europe. To ease this crowding, new regional routes have been developed to bypass these hub-spoke combinations. As a result, the regional airlines both serve and compete with major air carriers.

The trend towards hubbypass and point-to-point regional carrier operation has changed the original mission of regional airlines. This change requires new capabilities from the aircraft serving these missions. These new capabilities either are not met by existing aircraft or are not met effi- 
ciently. The current average route length or stage length is between 150 and 250 nautical miles for these regional transport routes.

These shorter routes are served primarily by small capacity, propeller-driven aircraft. Some predictions see the stage length increasing to over 300 nautical miles with maximum ranges of over 1000 nautical miles being required on some routes. In this case, the turbofan engine becomes competitive.

In addition to efficiency, airlines must consider passenger convenience, comfort and cabin noise levels. Regional airlines and their passengers will demand faster, quieter aircraft with more passengers on each flight so that they can serve markets efficiently and competitively. Passengers accustomed to the comfort, speed and in-flight amenities of major air carriers will come to expect the same attributes on the regional routes. This so-called seamless service between larger carriers and smaller carriers will be a major criterion in the design of new regional aircraft.

Finally, regional airlines must continue to be capable of operating from small community airports. Many of the im- portant smaller airports have runway lengths of as little as 5000 feet. In addition, the smaller communities have stringent noise requirements that must be considered. These FAR 36 noise requirements and the desire to keep passenger cabin noise at low levels will impose important constraints upon the designer.

\section{Objectives}

During the past year the mission of 12 Purdue senior student design teams was to develop and respond to a Request For Proposal (RFP) for a regional transport mission. This RFP contained performance requirements chosen by individual teams on the basis of their perception and analysis of the transport market as it will exist in 1995. Special emphasis was placed upon designing to cost, a cost that includes aircraft acquisition cost and operational cost (DOC). Designs incorporating unusual features and creativity were encouraged. The result of this study was not only a perception of what a regional transport should look like, but also an idea of what students thought the most important markets would be.

Although the semester provides a 14 week work schedule, each team had only 
about ten weeks to conceive and develop its design concept. This shortened time period was due to the fact that the first four weeks of the semester were used to develop market studies and to acquire special design skills such as aircraft weight estimation, design sensitivity techniques and other traditional techniques.

\section{Team Requirements}

Each design team was subject to stringent analytical, conceptual and reporting requirements for their design. It was required that extensive information on aerodynamic performance be generated together with stability, control and flying quality information. The structural loads, member layout and weights and balance information were also required. Coupled together with the weights information were the requirements for guarantees that the landing gear could support the ground loads and would meet minimum tip-over and take-off clearance requirements.

The ability to perform the required transport mission from take-off to cruise to landing with required reserves was rigorously checked using analytical procedures that ranged from highly preliminary to extremely sophisticated.
These checks used class-developed performance computer codes and, in many cases, the FLOPS (Flight Performance and Optimization) code developed by NASA/Langley and modified at Purdue for use on the personal computer. To obtain performance data it was necessary to have extensive engine data. Such data is usually a closely held secret guarded by engine manufacturers.

To remedy the problem of obtaining accurate engine data, two personal computer codes, ONX and OFFX, were used. These codes can match and generate crucial engine performance data such as fuel flow at various Mach number, altitude and power settings. These codes were used extensively by the USRA Teaching Assistant during the Summer of 1990 and a video tape and set of assignments were formulated for class use.

These codes were used to modify the engine cycle and inlet temperatures as required to meet the specific missions of the design team aircraft. In some cases this required extensive re-design of the three engine designs that the students were given at the beginning of the class.

The final result of each team's work was: a detailed 
100 page design report; an executive summary of this report; and, a 25 page mid-term report that was evaluated by a team of technical writing experts from the Thiokol Corporation. What follows is a summary of some of the data presented in these reports.

The value of time and the cost of speed

Time is money. Time is of value to a passenger on the regional transport, but it also costs money to acquire the speed necessary to save time. This cost is reflected in all of the empirical relations used to estimate aircraft cost.

Figure 1 shows the amount of time required to complete a trip as a function of airspeed. This so-called timescoping analysis shows that there is a knee in this curve. At Mach numbers or airspeeds above this knee, there is very little change in the trip time as Mach number increases. In general, this knee moves right to larger airspeeds when the range of the aircraft increases. For short range aircraft, it is not important that the aircraft be extremely fast.

Because of the market factors that governed each group's design, the 12 teams independently arrived at the conclusion that it was unnecessary to have the aircraft travel extremely fast. In addition, because aircraft acquisition cost increases with cruise Mach number, cruise speeds were kept down so that they ranged between Mach numbers of 0.70 and 0.82 . These cruise Mach numbers can be compared to longer range aircraft that may cruise up to Mach 0.90 .

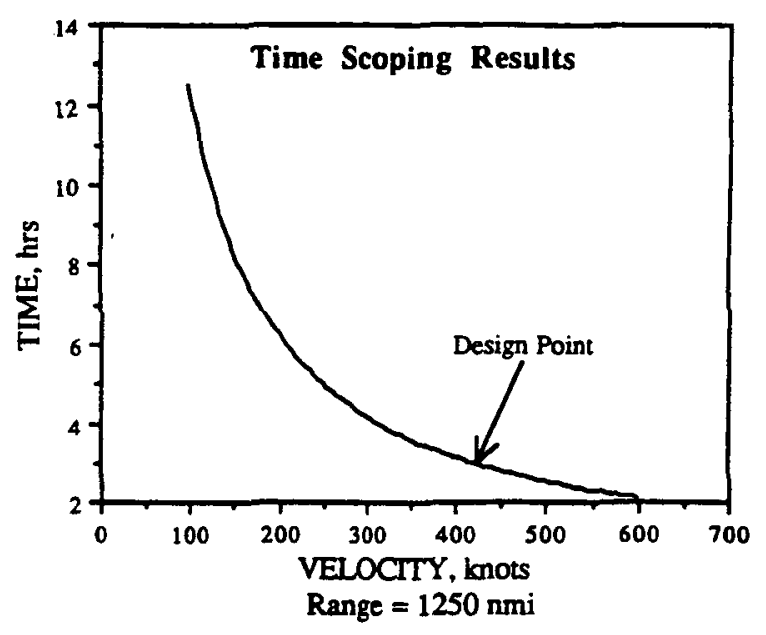

Figure 1 - Trip time vs. airspeed

Passenger loads, range and requirements

Recent trends in the regional transport business have been directed towards the development of aircraft with up to 100 seats and ranges up to 1500 nautical miles (nmi.). As a result, the RFP's developed by the 12 design teams displayed a wide range of seating and range objectives. Figure 2 shows this data for the 12 design groups and compares it 
to two other aircraft now in service.

The smallest aircraft developed at Purdue has a passenger capacity of only 50 passengers with a range of between 800 and 900 nautical miles (with reserves). The largest aircraft is designed to hold 90 passengers and had a range of 1650 nautical miles, comparable to the Fokker 100.

\section{Design Teams' Market Profile}

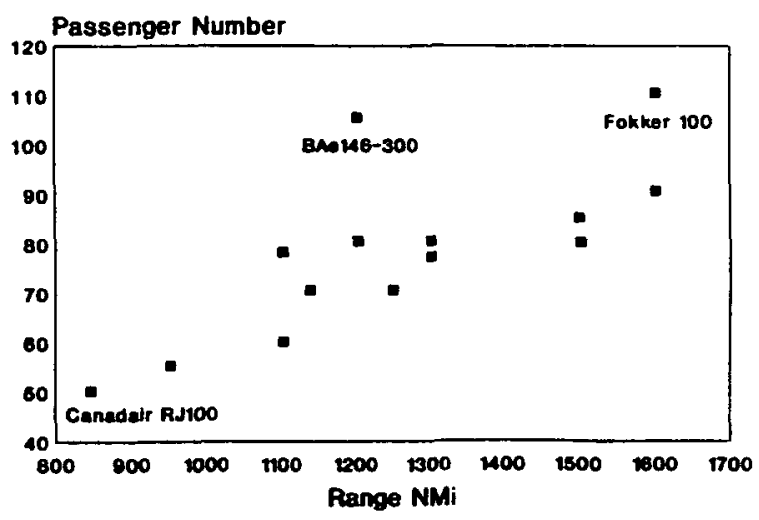

Figure 2 - Design team passenger number vs. range

Design groups identified the European and Asian markets as being more promising than the U.S. market. As a result, while they used FAR standards in their work, design teams also used the AEA or Association of European Airlines Requirements as a standard to meet.

While the AEA standards repeat many of the FAR requirements for safety, they also set minimum standards for passenger comfort in terms of such items as seat pitch. All 12 aircraft meet these AEA standards and use AEA guidelines to calculate direct operating cost (DOC). Let us now consider some of the designs generated by the design teams and their features. Note that all of these designs are required to carry a cockpit crew of two.

\section{The WAG-78}

The WAG-78 is a 78 passenger aircraft with a range of 1100 nautical miles. It is designed to cruise at $\mathrm{M}=0.80$ at 35,000 feet with an operational ceiling of 39,000 feet. The aircraft will take off from a runway with a length greater than 5500 feet on a standard day in Denver. This design is a modification of a design that has appeared during the past ten years and is shown in Figure 3 .

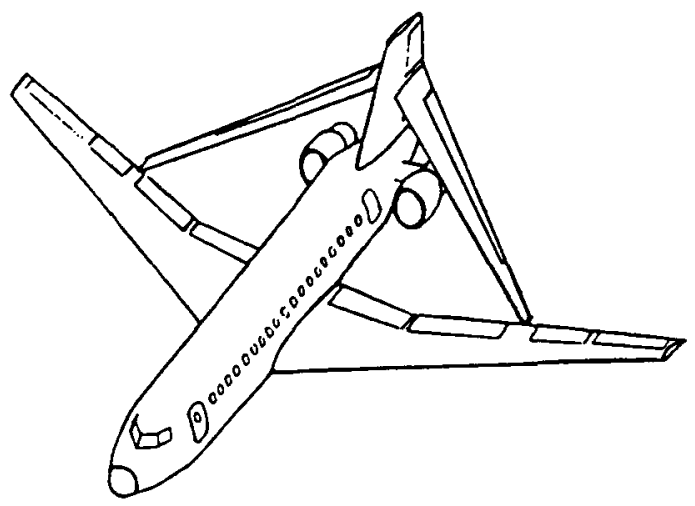

Figure 3 - WAG-78 Joined Wing Design 
The WAG-78 provides an example of a departure from conventional subsonic aircraft design because it uses the joined wing concept developed several years ago. This joined wing has a rear wing surface that acts both as a horizontal tail and as an external strut to stiffen and strengthen the wing. The take-off gross weight of this aircraft is 54,900 lbs. with an empty weight of 30,500 lbs. Some weight savings were achieved because of the joined wing structural design.

The WAG-78, like all the other student designs, was powered by a redesigned General Electric TF 34 engine. This engine was resized and slightly redesigned to develop a thrust of $11,900 \mathrm{lb}$.

Two engines were used for this design to satisfy one engine inoperative (OEI) requirements and so that the engines would be capable of developing thrust levels sufficient to meet the take-off requirements and one engine inoperative (OEI) criteria. The thrust-to-weight ratio for this aircraft is rather large so that the aircraft can climb rapidly to its cruise altitude.

The designers of the WAG-78 were conservative in their estimates of the number of aircraft that they could market. They predicted that they would be able to sell 175 aircraft over an 11 year development and production cycle. This 175 number did not include the 5 test aircraft that they chose for a development phase that was to last between 3 and 5 years. This unusually large number of test aircraft were thought to be necessary because of the new joined-wing design feature that they proposed to use.

The WAG-78 designers estimated a Development and Testing Cost of $\$ 810$ Million and production costs of $\$ 2.262$ Billion. A cash bucket analysis such as that shown in Figure 4 was used to estimate the price of this aircraft to be $\$ 20$ Million if the cost of capital is $18 \%$. Operating costs for an 1100 nmi. trip were estimated at $\$ 2060$ to give a low 3.6 cents per revenue seat mile assuming a $66.7 \%$ load factor.
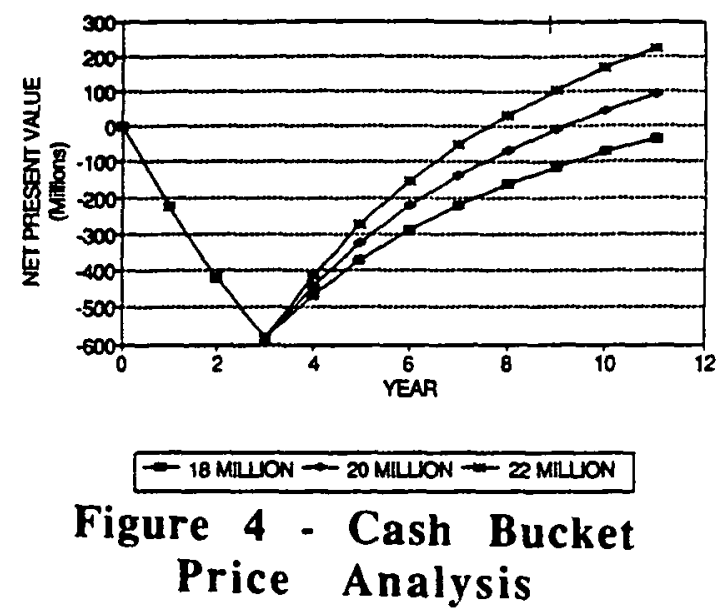

Purdue design - page 7 
The WAG-78 design team compared their design to the B Ae 146-100 and the DeHaviland Dash 8-400 and found that the WAG-78 cost 0.5 to 1 million dollars more than these other aircraft. On the other hand, it could be operated at a seat mile cost of about $10 \%$ less than the BAe $146-100$ and only slightly more than the Dash 8. The Dash 8 is a turboprop aircraft and, in its latest stretched version, its range has been reduced to 800 nmi. at a speed of 350 knots.

\section{The ARCA-60}

Design reviews with industrial representatives were held during both semesters of design team activity. Design representatives included a marketing authority, a propulsion and maintenance expert and an airline pilot. The airlines represented included Southwest Airlines, USAir and Northwest Airlines.

In all cases, the teams were encouraged to simplify their designs and to consider flight operations and maintenance. While this advice was valuable, it also tended to discourage configuration innovation. As a result, aircraft external features evolved to become somewhat traditional.
An excellent example of a well-conceived, traditional, DC9-like design is the ARCA-60, shown in Figure 5. This aircraft has seating for 60 passengers with an 1100 mile range and enough fuel to fly to an alternate airport $200 \mathrm{nmi}$. away and hold for 30 minutes. It has a maximum Mach number of 0.80 and cruises at 35,000 feet at $M=0.75$.

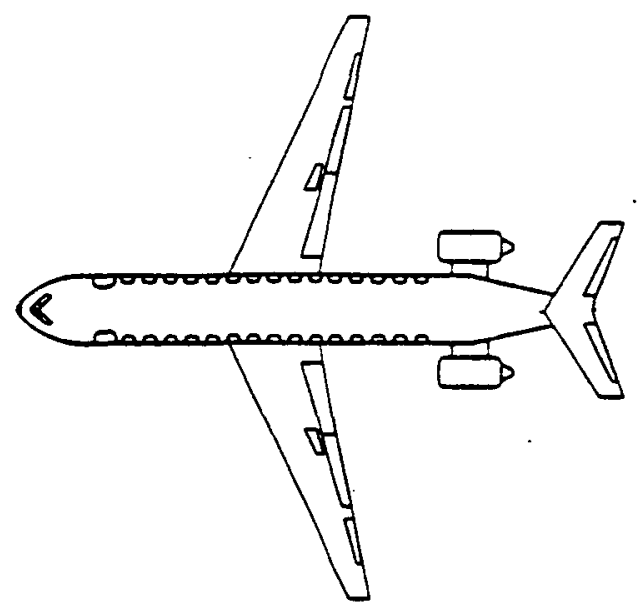

Figure 5 - The ARCA-60

\section{Aircraft}

Extensive studies were done by the ARCA-60 aerodynamicist to obtain an efficient airfoil shape for low drag. These efforts led to the choice of a NASA supercritical airfoil, the SC(2)-0412. An Euler code analysis of the section estimated the drag divergence Mach number of this section to be 0.75 . This code was necessary to accurately model the nonlinearities that occur in transonic flow. 
The ARCA-60 wing was mounted low on the fuselage to allow for aft mounting of the engines and easy storage of the landing gear. Aft mounting of the engines resulted in the requirement for a $T$-tail design. Although the c.g. movement during flight is minimal, the ARCA-60 requires a large tail volume to rotate the nose on take-off from short runways. The extra cruise drag from this configuration was regarded by the design team to be acceptable.

The ARCA-60 has a predicted TOGW of $60,300 \mathrm{lbs}$. and a wing loading of 75 psf at take-off. The wing quarter chord sweep is 20.4 deg. to help reduce torsional loads while maintaining aerodynamic efficiency. After extensive analysis, a taper ratio of 0.2 was chosen so that the lift distribution approached that of a minimum drag, elliptical spanwise lift distribution.

The thrust per engine was 9650 lbs. and is much lower than the WAG-78. With engine cost estimated at $\$ 2.4$ Million per aircraft, the ARCA60 is estimated to cost $\$ 19$ Million. This number is based on a production run of 300 and a cost of capital of $10 \%$. This latter cost is low compared to the $18 \%$ estimate of the WAG78 team. The ARCA-60 program is estimated to last for 20 years and to produce a profit of $\$ 819$ Million.

As shown in Figure 6, the cabin cross-section is designed for comfort. This feature of this design is also present in the other 11 designs.

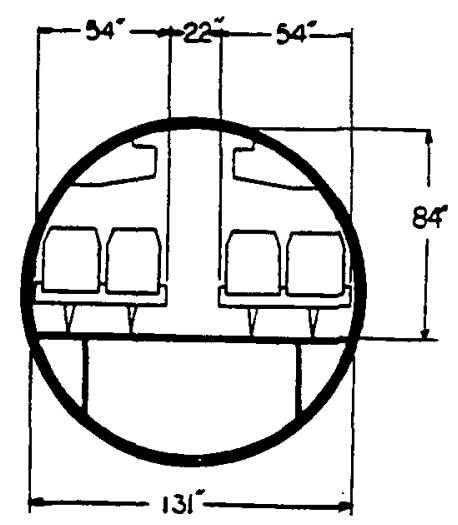

\section{Figure 6 - Cabin cross- section}

\section{The SRT-80 Aircraft}

The SRT-80 design, shown in Figure 7 , is representative of several designs produced during the project(note that this image is produced by a mesh generation program and some distortion in engine placement will occur when the computer screen image is printed). This aircraft resembles the $737 / 757$ class of aircraft with wing mounted engines. This aircraft can cruise at Mach 0.80 and carries 
80 passengers a distance of $1200 \mathrm{nmi}$. with reserves. It has a wing loading of 55 psf to allow it to take-off from 5500 foot runways at 2000 feet above sea level.
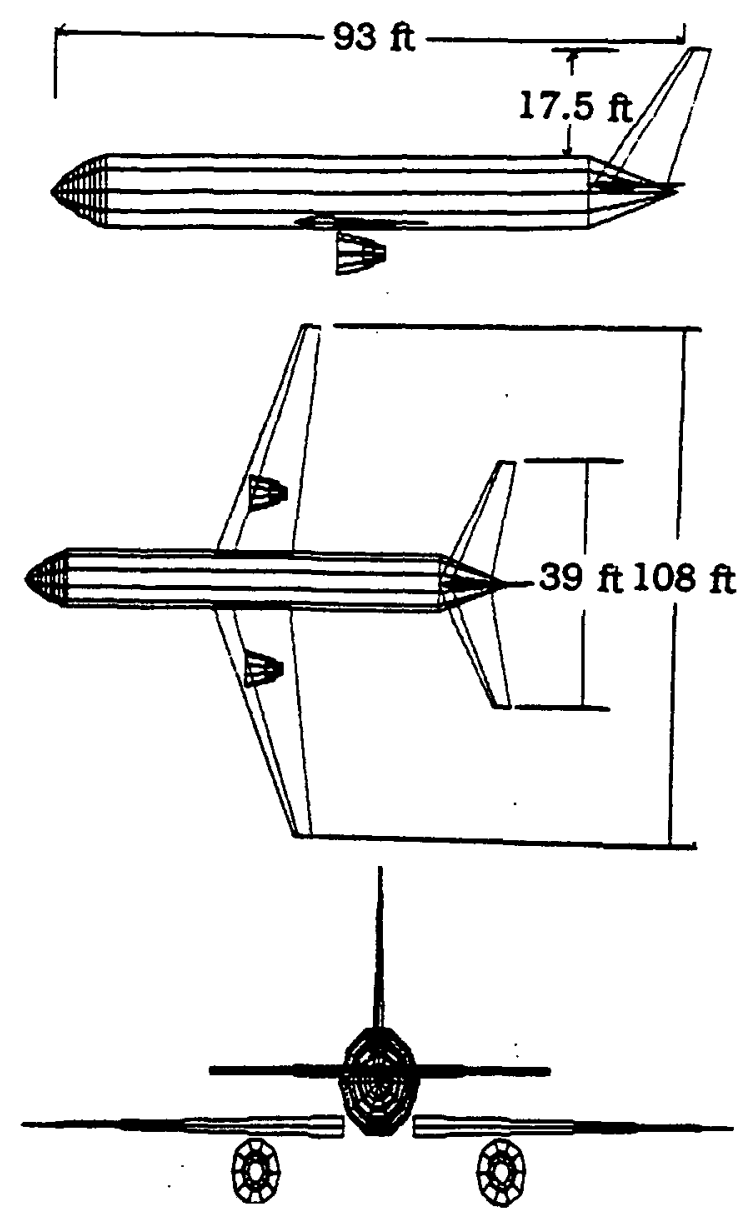

Figure 7 - The SRT-80

The aircraft has a span of 94 feet and a length of 93 feet. The wing itself has a dihedral angle of 5 degree for stability. At a design TOGW of 60,900 lbs. this aircraft will use 9400 lbs. of fuel to complete its mission. The engines on the SRT -80 are designed so that the in- tegrated airframe and propulsion units will generate 101 seat miles (nmi.) per gallon of fuel.

The engines are modified versions of the GE TF 34 turbofan design They were scaled up to increase the thrust from each engine. The TF 34 was selected by the SRT-80 team because of its superior fuel efficiency. The propulsion specialist increased the bypass ratio from 6.23 to 7.0 to increase thrust by almost $7 \%$ and to decrease fuel consumption by over $4 \%$.

Like most of the designs, the structure of the SRT-80 is composed primarily of aluminum, with small amounts of composites used in non-load bearing structure. The structure is estimated to comprise $40.1 \%$ of the TOGW. Passengers and baggage comprise an additional $31.6 \%$ while the systems and equipment form $3.3 \%$. The remaining weight is due to passengers and their baggage.

\section{The Wombat}

The last airplane to be reviewed is a blend of conventional design with a hint of nonconventional features. This design, shown in Figure 8 , began as a design that closely resembled the BAe-146 or the C141. The high wing design 
was judged by the designers to be desirable because of its handling qualities during the landing in the ground effect. Wing mounted engines were also desired for ease of access. Landing gear are stowed in a blister pod in the fuselage and meet tip-over criteria.

The Wombat has a wing span of 92.2 feet, a length of 105 feet and weighs 66,950 lbs. to give it a wing loading of 89 psf at take-off. The Wombat is designed to carry 70 passengers, but will also be available in a stretch version that will carry 100 passengers. The projected cost is $\$ 22$ Million.

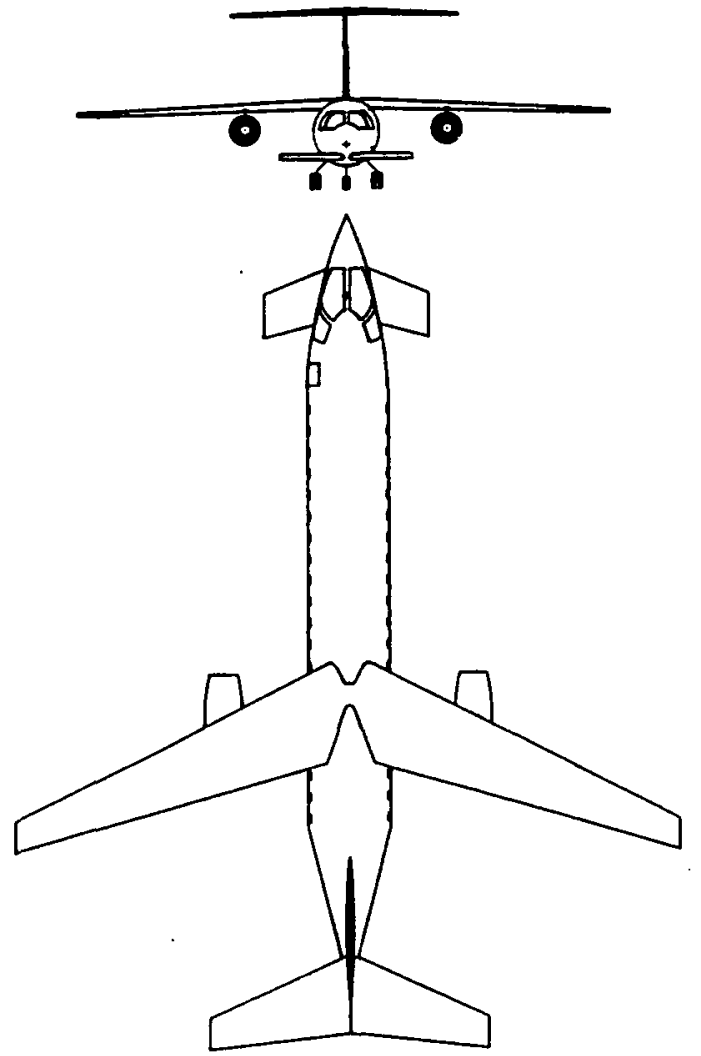

Figure 8 - The Wombat (note difference in scales)
During the design process the design team became concerned about cabin noise from the engines and overhead hydraulic lines as well as the potential for blade damage from an engine failure in flight. As a result, they moved the wing back instead of attaching the engines to the fuselage as a number of other design teams had done. This necessitated the addition of a canard to raise the nose at take-off. It also generated concern for the effects of the canard tip vortices on the engine intakes.

The aerodynamicist and the stability and control specialist cooperated to place the wing and canard properly to reduce trim drag in flight. The result was an optimized three surface aircraft shown in Figure 8.

The fuselage of this aircraft is to be constructed of Arall. This material has an organic fiber material sandwiched between layers of aluminum to form a composite material. This material should be safer and deaden sound from the engines better than conventional aluminum.

\section{Conclusion}

The Purdue design class considered the engineering/economic task of designing 
ing/economic task of designing a regional transport aircraft with turbofan engines. Market considerations drove this design to passenger capabilities of near 70 passengers. As a result, one of the three available engines, the GE TF 34 , was the clear choice of all 12 teams that participated.

One aspect of common agreement among the design teams was that the regional transport market should grow. As a result, a successful design will have a good chance of returning a profit to its investors. Because of the emphasis placed upon practicality and economy, most aircraft have a conventional appearance. In addition, most aircraft use minimal amounts of composite materials for construction and have conventional controls. On the other hand, all groups embraced supercritical airfoil technology.

The emphasis upon cost and price of the aircraft required a model to predict these numbers. The teams developed such models and the ability to judge the desirability of trading one technology against another. In the long run, it is the clear relationship between the market forces and the engineering decisions that will prove to be the most valuable aspect of this design experience.
In addition to the accomplishments of the class, several valuable pieces of software were developed by student Teaching Assistants. The most valuable of these is a Macintosh package that computes the price of the aircraft subject to financial information such as the cost of capital. In addition, the direct operating costs are estimated using an Association of European Airlines package. 